Douglas WILBUR*

Glen T. CAMERON**

\title{
Theory Meets Practice: Updating the Contingency Theory of Conflict Management with Insights from an Adroit Practitioner
}

\begin{abstract}
The contingency theory of conflict is nearing its third decade, but there is a lacuna in the literature about the development of strategy. Additionally, the contingency continuum and its stances are overdue for continued theoretical development. To address these theoretical issues, this project explores the inductively gathered knowledge of a nearly 40-year public relations (PR) practitioner about the use of aggressive and controversial public relations strategies. He codified his observation into a diagnostic software tool called the Playmaker Influence System. His observations have never been empirically examined despite an abundance of supporting anecdotal evidence. Therefore, this project employs a systematic review to determine if these contentious strategies have enough evidence in scientific literature to validate their existence. The findings revealed that sufficient evidence does exist to support their existence, and that they can be integrated into the Contingency Theory of Conflict Management.
\end{abstract}

Keywords: Contingency theory of conflict management, strategy and tactics, systematic review

\section{Introduction}

The contingency theory of conflict management is over 25 years old with over 200 scholarly articles. However, a major theoretical gap exists in regard to strategy implementation. The theory's linchpin is that organizations adopt a stance, which is a strategically chosen general disposition or orientation towards a public or an issue. These stances are arrayed along a contingency continuum, see figure one below, from pure accommodation to pure advocacy. Subsequent PR strategy flows logically from the chosen stance. Several stances were originally introduced because their existence was strongly supported by research literature (Pang, 2006). Nonetheless, contingency theorists never accepted that these would be the only stances. Discovering and adopting new stances would greatly assist in the study of strategy implementation.

* University of Missouri at Columbia, US, Douglas_wilbur@yahoo.com

${ }^{* *}$ University of Missouri at Columbia, US, CameronG@missouri.edu 
Figure 1. The Contingency Continuum.

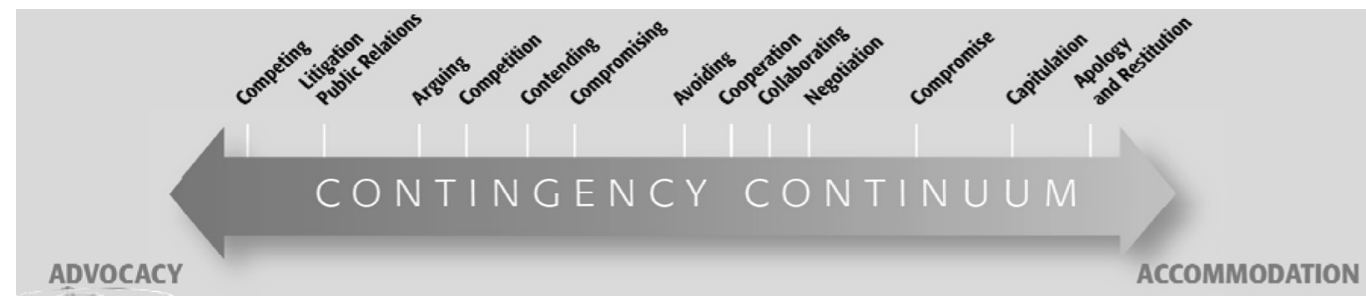

Contingency theory, being an open source theory, actively seeks new ideas and practices from practitioners. Alan Kelly ${ }^{1}$, founder of Playmaker Systems LLC with 40 years of industry experience, is such practitioner. His experience defending clients against highly controversial and ethically questionable strategies like baiting and using decoys is just one example. Through Kelly's (2006) extensive experience, he has developed a practical theory of influence and strategy initially codified in a book entitled, The Elements of Influence. He subsequently developed a software tool call the Playmaker Influence System. We chose to use Kelly's work because, as experienced communications practitioners, we believed that he has observed and recorded phenomenon that existed in practice but presented a gap in the literature. We also ascertained that his work had relevance to the development of the Contingency Theory of Conflict Management.

Playmaker theory proposes the existence of 23 strategies, referred to as influence plays, organized into three arch-classes and six sub-classes, and classified according to their strategic function. These categories and plays are graphically depicted in figure 2: Taxonomy of Influence Strategies (Kelly, 2018). The sub-categories, under closer examination, reveal that they are conceptually similar to stances. According to Kelly, sub-classes can be adopted by organizations as policies in the selection of strategies (A. Kelly, personal communication, 12 December 2017).

This present study serves one key purpose: we ask the testable question of whether or not there is precedence in the academic literature to justify the inclusion of the six Playmaker subclasses as stances into the contingency continuum. This would constitute a necessary and important progression for the contingency theory and make it more useful for practitioners. Expansion of the continuum, see figure one, can open future theoretical development through the connection of specific PR strategies to certain stances. 
Figure 2. Playmaker Taxonomy.
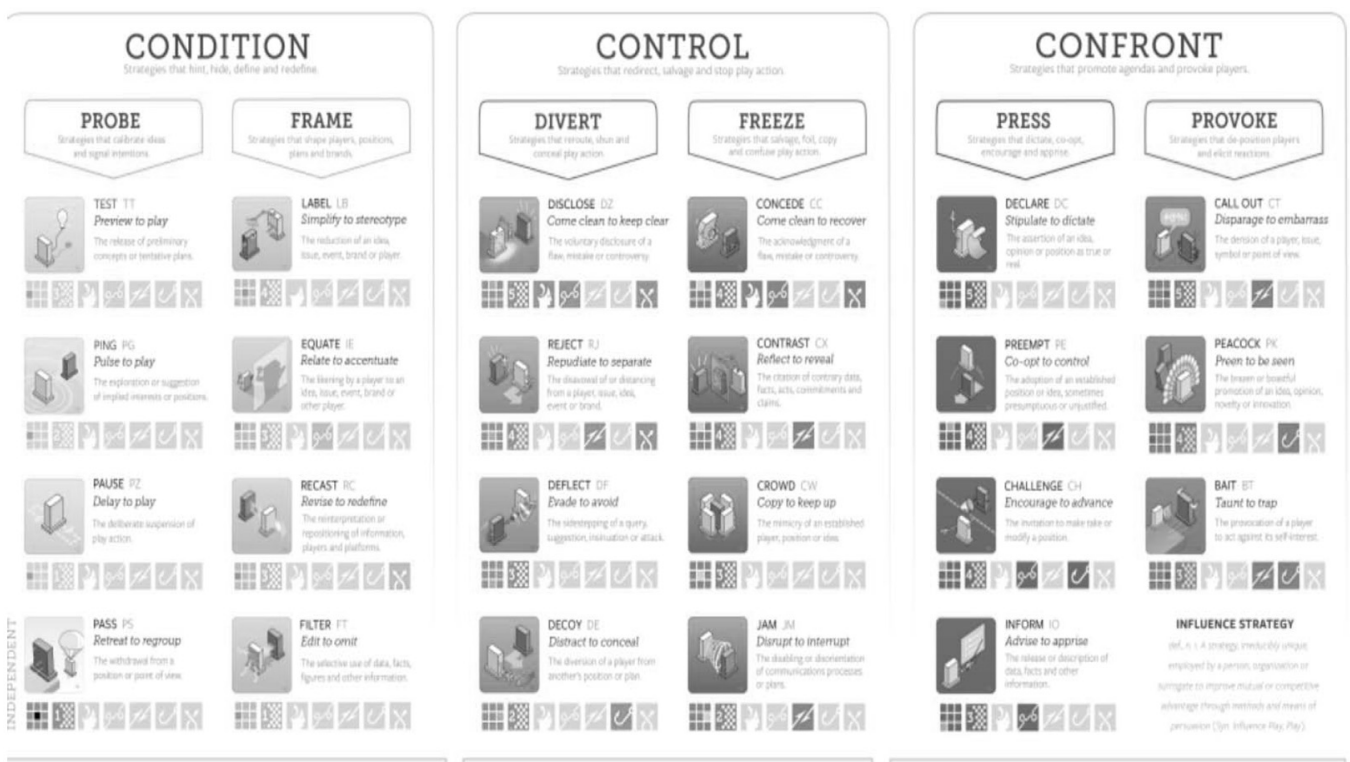

\section{Review of Literature}

The contingency theory of conflict management holds that public relations is, "The strategic management of conflict and competition in the best interests of an organization and, when possible, also in the interest of key publics" (Wilcox, Cameron \& Reber, 2015, p. 164). The core of contingency theory is that when faced with a problem, issue, crisis, etc., an organization will begin the process of strategic planning by examining a variety of relevant internal and external variables. The outcome of this decision-making process is the adoption of a strategically chosen stance that acts like a guiding policy from which subsequent strategies and tactics are developed. Furthermore, stances can change over time and in response to environmental conditions (Cameron, Pang \& Jin, 2008).

Most of the current stances were developed by Pang (2006) and have been integrated into textbooks and edited book chapters. He chose these stances from theories and their supporting literature that demonstrated that the stance did exist and has been employed by PR practitioners. For instance, leveraging William Benoit's (1995) Image Repair Theory as a rhetorical response to crises, like apology, have been adopted as a stance.

\section{Playmaker Systems}

Kelly was inspired to organize his work by chemistry's periodic table and biology's phylogenetic tree as metaphor-models to construct a complete ontology of influence strategies. They are organized into three general arch-classes: Condition, control and confront. These archclasses are merely a method to organize his taxonomy through a broad level description of the strategic functions they serve. Each of the three classes has two-subclasses for a total of six: Probe, frame, divert, freeze, press and provoke. He defines these strategies as, "irre- 
ducibly unique, employed by a specific person, organization or surrogate to improve mutual or competitive advantage through methods and means of persuasion" (Kelly, 2018, p. 45). Influence plays must adhere to certain criterion. First, they must be unique, and each should represent a mutually exclusive principle of influence. Second, they must be strategic in that they embody a plan of action that aims to achieve some goal. Third, they must have a causal ability to achieve certain effects, outtakes and outcomes. Finally, they must be intangible by exhibiting primarily abstract properties.

All of the plays are located on an interactive table called "The Taxonomy of Influence Strategies" on the Playmaker Systems website. Each is hyperlinked to a detailed description of the play that includes a play's definition, conditions where its use is ideal, associated risks and rewards, recommended countermeasures, collaborative strategies, and other pertinent information $^{2}$ (Playmaker, 2018). The essential difference is that influence strategies describe motive and approach while tactics describe the means of execution (Kelly, 2018). Thus, tactics extend beyond persuasive messages to encompass virtually any communicative behavior that can exert a causal effect upon the behavior of another. Examples of how this system works are presented in the discussion of the sub-classes below.

\section{Critiques of the Playmaker System}

There are two major potential criticisms of Kelly's work. First is that the Playmaker's conceptualization of strategy is inconsistent with how most Public Relations academics and practitioners understand it. This criticism is evident by examining one of the most prevalent and credible definitions of strategy from Cutlip and Center, which states, "What is the overall action and communication plan for achieving the program goal?" (2009). Playmaker elements are notably specific and primarily driven by the ambition to identify, name and organize units of influence and strategy on a kind of atomic scale. We must remember, however, that within the academic discipline of communication, most communication scholars cannot agree upon adopting a universally accepted single definition of what communication is (Dance, 1984). Thus, while one may not agree with Kelly's understanding of strategy and tactics, his work can still be appreciated as one method of perceiving reality.

The second critique of Kelly's system and its conceptualization of strategic communication and influence is that it might offend the moral and ethical sensibilities of some practitioners and scholars. Kelly conceived his system while employed as a practitioner and observer in the cutthroat public relations market of Silicon Valley (Kelly, personal communication, 12 December 2017). Even if an ethical practitioner does not use unethical strategies, some of their competitors certainly will.

Furthermore, Kelly's system could be appropriate suited for study under the theoretical framework of the contingency theory of conflict management. This is due the theory's assumption that conflict and competition are natural and unavoidable aspects of human nature. Since no theoretical definition of conflict has been presented in the literature, we have subsequently developed one which states,

Conflict is an active dispute between two or more parties over real or perceived goal interference.

Conflict can be constructive if protagonists are non-violent and rely upon persuasion. Adversaries often perceive each other as legitimate and accept the possibility of mutually acceptable outcomes. Conflict is destructive insofar as the methods employed are severe and intended to inflict various types 
of harm to the adversaries and place the very survival of one or more of the adversaries in jeopardy.

(G.T. Cameron, Personal communication, 10 November 2017).

Contingency theorists do not doubt or deny the importance of ethical behavior. They seek to inductively examine the reality of public relations in order to fulfill the mission of social science, which is to explain, predict and control. Now that the basics concepts of the Playmaker theory have been explained, we will delve into the specifics of its centerpiece, the Taxonomy of Influence Strategies.

\section{Condition Class}

The condition sub-class is defined as "Strategies that hint, hide, define and redefine"(Kelly, 2018, p. 18). They are the least assertive of the system and most open to accommodation. Since conditioning aims to prepare markets or public spheres for future strategies, they manifest as more subtle and indirect than the other two sub-classes (Playmaker, 2018). As a set of contingency theory stances, condition class sub-categories would fill a gap between capitulation and Yang and Lee (2019) discussed how cultural factors like public distrust of institutions are becoming more important in a post-truth society. During a crisis of conflict, an organization may not be able to assume that a skeptical public would believe their messages. Adopting a condition sub-class strategy like probe as an initial stance would allow an organization to stall and gather more data about a public's beliefs in order to adopt the most optimal future stance."

\section{Probe}

The probe sub-class is conceptually defined as, "Strategies that calibrate ideas and signal intentions." (Kelly, 2018, p. 20). Probing strategies include the test, ping, and pause, which give players their best opportunity to ease into a marketplace, to feel it out, and vice versa. They allow players to gauge current reactions to their messaging, but also to experiment with new ideas. Ping, which can be used to signal implied interests or positions (Playmaker, 2018), manifests tactically as a variety of subtle or oblique messages that suggest a person or organization could do something in order to assess reactions. These reactions can then inform future decision-making. As a stance, the ping could fall into the middle of the contingency continuum, but usually when an organization lacks sufficient information to adopt a more specific stance.

\section{Frame}

The Frame sub-class is conceptually defined as, "Strategies that shape players positions, plans and brands" (Kelly, 2018, p. 20). The frame sub-class speaks to an organization's attempt to control its own position, image, reputation, or brand by shaping perceptions and attitudes of others, typically (but not exclusively) in the public sphere. Frame's four strategies are label, equate, recast and filter, which influencers typically employ as a method for creating conditions particularly advantageous for an organization. A case study by Bae and Park (2011) reviewed the Korean news media's framing of a post-crisis philanthropic donation by the Samsung Corporation. Samsung was trying to fulfill cultural expressions of apology with the donation, but the news media recasted the donation as the company trying excuse itself. 
Because this description of framing is conceptually consistent with media framing and agenda building theory, it can be argued that framing is a tactic since it is often used as such in the development of press releases and other PR devices. Kelly would counter-argue that there are at least four different strategies by which framing is achieved or frames are constructed, and each could meet his criteria as an influence strategy (Kelly, 2018).

One framing strategy is equating, which works to create a perceptual association between an organization, idea, issue, event or brand to another desirable one (Playmaker, 2018). Whether it is to frame a competitor, collaborator, or independent player, the intent of the equate play is to associate a target with an idea, issue, event or brand that symbolically transfers new qualities or characteristics to that player. As a stance, it could fall into the left middle of the contingency continuum. Shaping perceptions in the public sphere is a form of advocacy since the desired perceptions are those that benefit the organization. It is a mild form of advocacy, so logically it would be a precursor to the future adoption of a more assertive, advocative stance.

\section{Control Class}

The control class is defined as, "Strategies that redirect, salvage and stop play action" (Kelly, 2018, p. 19). Its sub-classes are divert and freeze where organizations adopt more assertive and pro-active strategies that defend positions or influence their standing in a marketplace. It can also be used defensively, such as in crisis response, and to prevent an undesirable outcome. Control class sub-categories could fill a current gap on the contingency continuum between avoiding and compromising. For instance, Yang (2016) discovered that cultural factors led Chinese NGO's to predominantly use an advocative stance that included denial and excuse. These can create problems, especially when they are actually at fault during a crisis. Control class strategies like divert might offer another lower risk stance they can embrace.

\section{Divert}

The divert sub-class is conceptually defined as, "Strategies that reroute, shun and conceal play action" (Kelly, 2018, p. 21). Diverting plays are typically used to indirectly counter opposing positions and agendas, or to remove them as obstacles by shifting the attention of stakeholders from another player's actions toward a topic less threatening to an organization. Divert has four strategies: Disclose, reject, deflect, and decoy that are as the name implies: diversionary in nature. The optimal conditions are to keep uncooperative segments of a marketplace, or potential stakeholders, in the public sphere in a position where the organization can either cultivate or marginalize them (Kelly, 2018).

An exemplary diverting strategy is disclosure, which relies on the voluntary disclosure of misconduct or mistakes (Playmaker, 2018). This strategy is essentially acceptance of blame and expression of mortification. Tactically, it can manifest as an apology followed by corrective action. As a stance, it could fall into the left middle of the contingency continuum. While it can describe an accommodative oriented stance, it more correctly represents a form of advocacy, or what is most often a defensively oriented one. This would make it unique on the contingency continuum. 


\section{Freeze}

The freeze sub-class is used largely to control and mitigate the negative effects of harms caused by another player, such as a competitor or some opposing factor. The freeze category is conceptually defined as, "Strategies that salvage, foil, copy and confuse play action" (Kelly, 2018, p. 21). Like its diversionary sibling detailed above, freezing plays are designed to inhibit or reverse the movement or motives of other players, most often by intervening in their implementation and thus preventing further erosion to the principal player's position and agenda. Pang, Jin and Ho (2016) discussed how organizations can face a perpetual threat from governments in the form of increased regulations in response to real or perceived unethical behavior. Employing a freeze strategy might be useful in these contexts. Engaging in lobbying to prevent the imposition of new regulations might represent a freeze strategy.

The four freezing strategies are, concede, contrast, crowd and jam. Consider, for example, the contrast play where an organization counters an allegation through the citation of contrary data, facts, acts, commitments, and claims (Playmaker, 2018). This can often be seen in an accuser's attack, and it is frequently used during many political campaigns. As a stance, contrast could fall into the advocacy portion of the contingency continuum given that it is fundamentally assertive in nature.

\section{Confront Class}

The confront class is defined as, "Strategies that promote agendas and provoke players" (Kelly, 2018, p. 19). The confront class is composed of the press and provoke sub-classes that are highly advocative and assertive in nature through high-engagement strategies that are clearly not accommodative. To confront is to directly challenge other players and to intervene in their actions and plans. The goal is to influence and alter another player's behavior, or a market's makeup in order to advance one's own agenda (Kelly, 2018). Confront sub-class strategies might add depth on the advocacy side of the contingency continuum between arguing and litigation. Jeesun and Cameron (2016) discussed the unique problem caused during a crisis when variance between avowed and ascribed organizational identities. Adopting a confront sub-class strategy to protect an organization's identity may be necessary in order to combat other agents attempting to ascribe a false identity.

\section{Press}

The press sub-class is conceptually defined as, "Strategies that dictate, co-opt, encourage and apprise" (Kelly, 2018, p. 21). The press sub-class has four strategies: declare, preempt, challenge and inform. These describe deliberate attempts by an organization to position itself into a marketplace or other desired position in the public sphere. This sub-class is ideal for new or marginal organizations since they help to raise brand awareness and build their reputations. A good example of pressing is the declare play, where another player's claims are directly challenged through the citation of facts, data, acts or claims - all to contradict another player's messages or applied symbols. (Playmaker, 2018). Feng, Yang and Duo (2017) discuss how western journalist essentially adopted challenge and declare strategies as defacto stances when they interact aggressively with Chinese Government officials at press conferences. Tactically, this could manifest when a weaker organization sponsors a study that 
contradicts the claims of a superior competitor concerning the benefits or risks of an offered product or service.

\section{Provoke}

The provoke category is conceptually defined as, "Strategies that de-position players and elicit reactions" (Kelly, 2018, p. 22). Provoke strategies include the call out, peacock and bait, which are most often offensive in nature. They aim to remove a player, usually a rival, from its current position and force it into a less desirable posture. This definition seems to have a distinctly economic/marketing focus since the de-positioning of a rival is commonly understood to displace a competitor from a favored position (Kelly, 2018). However, it does have a broader application that could equally apply to activists trying to prevent the change of a law supported by oppositional lobbying groups.

One play in the provoke sub-class is bait, which involves the provocation of another player - again most often a rival or some opposing force - to react irrationally. One condition that justifies this strategy is when a competitor is known to be sensitive about some identified topic or shortcoming and has a history of overreaction (Playmaker, 2018). As a tactic, it might manifest as a false accusation from an activist group in order to compel a change in policy or increase in corporate social responsibility efforts that benefit the activist group. As a stance, it could fall into the far left of the contingency continuum representing pure advocacy executed in an aggressive fashion. Given the literature reviewed, the study's primary research question is offered below.

RQ 1: Do each of the six sub-classes of the Playmaker taxonomy have sufficient precedence in the academic literature to support their inclusion into the contingency continuum as stances?

\section{Methods}

A proven method to answer this research question is to conduct a systemic review, which is a scientific method for conducting a literature review. It is a qualitative method that can include a quantitative meta-analysis if desired. However, we opted to exclude the meta-analysis from this study as it would make the scope unmanageable. It collates empirical studies that fit deductive eligibility criteria in order to answer a specific research question. Systematic reviews have clearly stated objectives with pre-defined eligibility criteria for study selection that are explicit, reproducible methodology (Petticrew \& Roberts, 2006).

This project is guided by the widely accepted standard entitled systematic reviews and meta-analyses, or PRIMSA for short. It consists of a 27-item checklist and a four-phase flow diagram. The checklist includes items deemed essential for transparent reporting of a systematic review; however, some of the steps are specific to meta-analysis that is not relevant here (PLoS Medicine, 2009). Checklist items one through five were completed above, so we start with steps six through twelve, during the development and implementation of the search protocol $^{3}$. 


\section{Eligibility and Study Selection}

We accepted both quantitative and qualitative English language articles. Only full-length original research articles from peer-reviewed scholarly journals were selected. The unit of analysis was the entire scholarly article. We relied upon this to satisfy checklist item 12, risk of bias in individual studies. We trust that the peer review process mitigated bias threats. Thus, the first eligibility criteria are that the phenomenon discussed in the reviewed paper had to exist in reality as human communication behavior. Human communication can be defined as the process where two or more people stimulate meanings in each other's minds through verbal and non-verbal messages that can assume many formats and be disseminated through a variety of channels (Richmond, McCroskey \& Hickson, 2012).

Thus, all sub-disciplines of human communication from non-verbal to strategic communication were eligible for review. We also included certain articles from the psychological and business literature as long as it addressed a human communication behavior. The second eligibility criteria were that the communication behaviors under consideration had to reasonably fit with Kelly's definition of the sub-class. The code book consisted of the components of the definitions of the sub-category and its subordinate plays. These definitions were descriptive enough to provide enough detail for coding

The two coders used the following process to determine whether to retain or exclude an article from further analysis, and then to ascertain which Playmaker sub-class it supported. The first step was to determine if the paper involved a human communication behavior. If one of the coders determined that it did not, it was excluded from the study. The second step was to determine which of the Playmaker sub-classes the paper best fit into. If the coders disagreed, a moderator broke made a decision and either retained or culled the article. The final step was to determine if the definitions provided in the article adhere to the Playmaker definition. Great care was taken to ensure that selected articles were code-able, and several were recoded several days after the initial review. The PRSIMA standards don't have a mechanism to differentiate between manifest and latent content. Thus, we assumed a whole article approach to analysis. Using Holsti's formula, our inter-coder reliability was 100 percent (Stacks, 2017).

\section{Information Sources and Search Terms}

A test of various databases was conducted with the search terms and the following databases were selected: Communication and Mass Media Complete, Business Source Premier, PsycINFO and Academic Search Complete. The search terms were developed based upon four criteria. The first sets of search terms were the Playmaker strategies and their definitions for each sub-class. Since each strategy is logically consistent with the respective sub-class, their use made sense. The second set of search terms were derived from Kelly's conceptual definitions of the sub-classes. The third used the Merriam-Webster thesaurus to identify words that are nearly equivalent to a search term from the definition. For instance, using the definition of provoke, "Strategies that de-position players and elicit reactions" (Kelly, 2018, p. 22). Thus, conceptually similar search terms were foment, insult, incite. The final criterion was the researchers' knowledge of theory and concepts. Examining the de-position portion of the provoke definition, there is an obvious connection to positioning theory in both PR and marketing contexts. All of these terms were supplemented by a set of secondary terms used for all six of the sub-classes. Some of these were: advertising, journalism, mass media, interpersonal communication, and small group communication. 


\section{Study Selection}

The authors screened all of the articles, about 600 in total. First, we assessed the abstract to determine if the paper discussed a human communication behavior that was conceptually consistent with the respective sub-class. Second, we searched for a definition, explicit or implied, of the relevant search terms. Unless the paper offered an explicit definition or sufficiently explained how its authors understood the definition of the search term the study was omitted. The final criteria to validate each of the Playmaker sub-classes for inclusion onto the contingency continuum was the requirement of at least five manifested, unique communication contexts. This was an arbitrary decision, but necessary to ensure that there was sufficient evidence to support the existence of a sub-class. For instance, the provoke sub-class could be employed in the contexts of political communication, conflict communication, advertising, marketing communications and international communications. A 30 empirical article minimum was set for each category. Thus, given the six categories, a total sample size goal of $(\mathrm{N}=180)$ was sought. Due to space limitations, we limited inclusion of citations for these articles to those discussed in the findings section ${ }^{4}$.

\section{Findings}

\section{Probe}

The probe sub-class is a policy for using communicative messages, symbols or behaviors as a form of field research, while signaling the capability or intent to take some action (Kelly, 2018). A thorough review of the literature offered evidence of a conceptually similar human communication phenomenon consistent with Playmaker's conceptualization of probing. For instance, signaling theory examines the intentional communication of information by individuals and organizations in order to create a positive image of otherwise unobservable qualities to external stakeholders. A company might use CSR as virtue signaling to assess how it can influence a customer's assessment of product pricing (Jung, Nelson, Gneezy \& Gneezy, 2017). In an interpersonal context, employees might use expressions of dissent with a company's activities or leadership to signal their possible intent to leave. The response to this dissent provides employees with feedback that assists in their employment decision-making (Kassing, Piemonte, Goman \& Mitchell, 2012). As a stance on the contingency continuum, probing would fall into the middle between pure advocacy and accommodation. It is essentially orientation towards assessment, which will probably change as an organization gathers sufficient evidence to determine a change in stance. As a specific public relations strategy, it could manifest as general use of engagement designed to gain feedback while refusing to commit to a more specific position.

\section{Frame}

The framing sub-class is one where an organization attempts to control its brand, reputation or actions by defining or redefining itself in a certain manner. Much of the relevant literature relies upon either media framing as defined by Entman (1993) or Tversky \& Kahneman (1981) in their work on prospect theory. In both theories a strategic communicator is attempting to frame themselves, a rival, or a topic in order to shape the perceptions of others in a man- 
ner beneficial to the framer. For instance, de Bruijn and Budding (2016) discuss how to employ the gain and loss frames from prospect theory in order to influence people's perception of eating fruit with the goal of increasing personal daily consumption. Wilbur (2106) discussed how framing could be employed in a specific public relations context to benefit a public. Organizations can adopt it as a stance, whereby they will pursue a variety of framing strategies in order to create the conditions they need to shift to another stance. Since framing is ultimately advocative and assertive, it would fall towards the advocacy side of the continuum. Nevertheless, it is not very assertive in nature, so it would be closer towards the middle of the continuum.

\section{Freeze}

The freeze sub-class represents a set of policies to control and mitigate damage to reputation, credibility, trust and other crucial factors for managing one's image in the public. For instance, Fravel (2011) discusses China's use of communicative delay tactics to stall the formation of diplomatic agreements until it achieved certain strategic advantages. Searching the term freeze only yielded articles about refrigeration, thus most of the supporting articles were identified through freeze strategies. The freezing strategy has a strong precedence in the crisis literature since it is a form of apology (DiStaso, Vafeiadis \& Amaral, 2015). The jam strategy was also identified since it is a specific form of activism that matches very well with Playmaker definition. Mpofu (2017) discusses how engaging in aggressive protests employed as publicity events, like blocking traffic, disrupts societal routines. These events are inherently newsworthy and can easily attract media attention to a cause or issue. In this case, a marginalized group is attempting to challenge a rival ideology that it views as a threat to its image. As a stance, freezing is clearly a form of assertive advocacy, but its general orientation is defensive in nature. Thus, it would probably fall towards the center of the advocacy side of the contingency continuum.

\section{Provoke}

The provoke sub-class is composed of strategies intended to elicit reactions, primarily from competitors, that de-position them in their markets (Kelly, 2018). The concept of media provocation is well established, and the goal is to influence people to act in a certain manner that benefits the provocateur. Driessens (2013) discussed how celebrities use publicity events to provoke an audience into joining them in behaviors that violate established societal norms and values. McCosker (2014) identified how Internet trolls deliberately use provocation to incite a negative effect and other dysfunctional behaviors from their target to achieve some outcome desired by the troll. Boudana and Segev (2017) identified that elite newspapers from western nations, such as Die Welt and The New York Times engaged in provocation of readers to gain acceptance of their country's foreign policy towards North Korea. Given this review, it can be concluded that provocation is, in fact, a communication behavior that is actually practiced with the intent of influencing the behavior of others in a manner that benefits the provocateur. As a stance on the contingency continuum, it would fall very close to pure advocacy given its aggressive nature. 


\section{Discussion}

We initiated this exploratory research project because Alan Kelly's work made strong,

Intuitive sense. Furthermore, the strategies he identified, organized and detailed were strongly supported by anecdotal evidence. Scientists cannot accept claims based upon intuition, anecdotal evidence. Thus, the logical first step into examining whether Kelly's observations are legitimate is to examine previous research in order to identify if other scholars have recorded conceptually similar phenomenon through scientific processes. If this step yielded evidence to support these observations, then a precedent for future research is justifiable. Our systematic review did reveal sufficient evidence that the sub-classes of the Playmaker ontology and their strategies do exist in reality as human communication behaviors.

\section{Practitioner Implications}

There are two primary implications for practioners in this study. First, ethically questionable and overtly aggressive PR tactics can be identified, classified and analyzed in a systematic manner that allows for their use to be explained and predicted. The ability analyzes these tactics in a formal and systematic manner creates the platform necessary to manage competitor usage of them and neutralize the threat they pose. The second practical implication is that this research sets a precedent for other practitioners to create their own systems to classify and react to aggressive PR threats. Kelly's system only offers one way to potentially perform this task, as other methods may be developed. Kelly's principal contribution is to demonstrate that managing threats can be done effectively. Management of these threats creates opportunities for PR firms to expand their business model and create more value for their clients.

\section{Theoretical Implications}

From a theoretical perspective, this study has provided sufficient evidence to warrant the inclusion of the Playmaker sub-classes into the contingency continuum. This is consistent with the initial methods of identifying stances. While much more theoretical work is required to improve and develop both the continuum and the contingency theory of conflict management, basic theoretical development has progressed slowly during the past decade. Consequently, this study offers a good platform to expedite that process. This is especially relevant in the sense of competition, which we define as, "Employment of strategic communication assets, (public relations, advertising, branding and others), as well as marketing assets, (product, pricing, distribution and others), that an organization uses to distinguish itself from its competitors in a manner that provides them with a competitive advantage" (G.T. Cameron, personal communication, 10 November 2017).

\section{Limitations and Conclusions}

This study has several limitations, the first of which is the contingency continuum itself. We fully acknowledge that the continuum lacks a desirable degree of mathematical precision. Ideally it should assume the form of a scale that can be quantitatively measured. Additionally, certain existing stances like negotiation can assume a wide variety of variations that 
would constitute its own scale. Contingency theorists are currently working to improve these deficiencies, but this practice will take some time. Moreover, one could claim that our use of many search terms casts a wide net capable of catching support for any concept. While we did use a number of search terms, we derived these from the Playmaker definitions. This research is essentially a qualitative study and lacks the mathematical precision used to reduce bias in quantitative research.

This study began in pursuit of the testable question: Whether or not there is precedence in the academic literature to justify inclusion of the six Playmaker sub-classes as stances into the contingency continuum. Based upon our findings, we can emphatically answer yes. This is, however, only a starting point. Future research is needed to examine how and to what extent these strategies manifest. We must also assess how practitioners use them and defend against their use.

\section{Notes}

${ }^{1}$ Allen Kelly did not offer or provide the authors with financial or material compensation or incentives for this project. All he provided was documentation about his system and his time answering our questions over the phone or via email.

${ }^{2}$ The taxonomy can be found at: https://www.playmakersystems.com/playmaker-system/the-taxonomy/

${ }^{3}$ Reviewer Note: Our PRIMSA checklist is located in a separate document, submitted with the paper, and titled 'reviewer support document.' It explains in detail how we implemented the checklist. It also contains a detailed list and explanation of search terms.

${ }^{4}$ Reviewer Note: All of the citations are located in Appendix A: Bibliography-Code Book. I have submitted along with the manuscript for your analysis. Due to space considerations, we will adheret to the editor's decision whether or not to include this in the manuscript.

${ }^{5}$ Note to Reviewers: All six of the plays I described from the taxonomy chart share the same htttp address. To access the box with specific information about a play you must go to the chart and click on the play. There is not direct way to access the play box. Thus, I use 1 citation for all six plays.

\section{References}

A. Kelly, Personal communication, 12 December 2017.

Bae, J., \& Park, S.-A. (2011). Socio-Contextual Influences on the Korean News Media's Interpretation of Samsung's \$847.6 Million Donation. Journal of Public Relations Research, 23(2), 141-166.

Benoit, W.L. (1995). Accounts, excuses, and apologies: A theory of image restoration strategies. Albany, NY: State University of New York Press.

Boudana, S., \& Segev, E. (2017). The Bias of Provocation Narratives in International News. International Journal Of Press/Politics, 22(3), 314-332. doi:10.1177/1940161217704968.

Cameron, G.T., Pang, A., \& Jin, Y. (2008). Contingency theory: Strategic management of conflict in public relations. In T.L. Hansen-Horn \& B.D. Neff (Eds.), Public relations: From theory to practice (pp. 134157). New York: Pearson.

Cheng, Y., \& Lee, C.-J. (2019). Online crisis communication in a post-truth Chinese society: Evidence from interdisciplinary literature. Public Relations Review, 45(4),

Dance, F. X. (1984). What is communication? Nailing Jell-O ${ }^{\circledR}$ to the wall. Association for Communication Administration Bulletin, (48), 4-7. 
de Bruijn, G., \& Budding, J. (2016). Temporal Consequences, Message Framing, and Consideration of Future Consequences: Persuasion Effects on Adult Fruit Intake Intention and Resolve. Journal of Health Communication 21(8), 944-953. doi:10.1080/10810730.2016.1179366

DiStaso, M. W., Vafeiadis, M., \& Amaral, C. (2015). Managing a health crisis on Facebook: How the response strategies of apology, sympathy, and information influence public relations. Public Relations Review, 41(2), 222-231. doi:10.1016/j.pubrev.2014.11.014

Driessens, O. (2013). 'Do (not) go to vote!' Media provocation explained. European Journal of Communication, 28(5), 556-569. doi:10.1177/0267323113493253

Dulek, R. E., \& Campbell, K. S. (2015). On the dark side of strategic communication. International Journal of Business Communication, 52(1), 122-142. doi:10.1177/2329488414560107

Entman, R. 1993. "Framing: Toward Clarification of a Fractured Paradigm." Journal of Communication 43(4):51-58.

Fravel, M. T. (2011). China's strategy in the South China Sea. Contemporary Southeast Asia 33(3), 292-319.

Fisher, E. (2017). A Systematic Review and Meta-Analysis of Predictors of Expressive-Language Outcomes Among Late Talkers. Journal Of Speech, Language \& Hearing Research, 60(10), 2935-2948.

G.T. Cameron, Personal communication, 10 November 2017.

Jeesun K., \& Cameron, G. T. (2016). When Cousins Feud: Advancing Threat Appraisal and Contingency Theory in Situations That Question the Essential Identity of Activist Organizations. International Journal of Communication (19328036), 10, 1934-1949.

Jung, M. H., Nelson, L. D., Gneezy, U., \& Gneezy, A. (2017). Signaling virtue: Charitable behavior under consumer elective pricing. Marketing Science 36(2), 187-194. doi:10.1287/mksc.2016.1018

Kassing, J. W., Piemonte, N. M., Goman, C. C., \& Mitchell, C. A. (2012). Dissent expression as an indicator of work engagement and intention to leave. Journal of Business Communication 49(3), 237-253. doi:10.1177/0021943612446751

Kelly, A. (2006). The elements of influence: The new essential system for managing competition, reputation, brand, and buzz. New York: Plume Books.

Kelly, A. (2018). White paper Playmaker system 3: An update of the Playmaker Influence System. For analysts, strategists and students of influence. Retrieved from http://www.playmakersystems.com/wp-content/uploads/2018/04/Playmaker-System-3-White-Paper-vZ5.pdf .

McCosker, A. (2014). Trolling as provocation: YouTube's agonistic publics. Convergence: The Journal of Research Into New Media Technologies, 20(2), 201-217. doi:10.1177/1354856513501413

Mpofu, S. (2017). Disruption as a communicative strategy: The case of \#FeesMustFall and \#RhodesMustFall students' protests in South Africa. Journal of African Media Studies, 9(2), 351-373. doi:10.1386/jams.9.2.351_1

Pang, A., Jin, Y., \& Ho, B. M.-K. (2016). How crisis managers define ethical crisis communication practice in Singapore: identifying organizational factors that influence the adoption of ethical stances. Media Asia, 43(3/4), 191-207.

Pang, A. (2006). Conflict positioning in crisis communication: Integrating contingency stance with image repair strategies. Retrieved from MOspace Institutional Repository.

Petticrew, M, Roberts H. (2006). Systematic reviews in the social sciences: a practical guide. Malden, MA: Blackwell Publishing.

Playmaker Systems ${ }^{5}$. (2018). Taxonomy of influence plays. Retrieved from https://www.playmakersystems. com/playmaker-system/the-taxonomy/.

Richmond, V.P., McCroskey, J.C., \& Hickson, M.L. (2012). Nonverbal Behavior in Interpersonal Relations ( $7^{\text {th }}$ ed.). Boston: Allyn \& Bacon.

Reber, B. H., Cropp, F., \& Cameron, G. T. (2003). Impossible odds: Contributions oflegal counsel and public relations practitioners in a hostile bid for Conrail Inc. byNorfolk Southern Corporation. Journal of Public Relations Research, 15(1), 1-25.

PLoS Medicine. (2009). The PRISMA Statement for Reporting Systematic Reviews and Meta-Analyses of Studies That Evaluate Health Care Interventions: Explanation and Elaboration. In A. Liberati, D.G. Altman, J. Tetzlaff, C. Mulrow, PC. Gøtzsche (Eds.), PRIMSA Statement.

PLoS Med 6(7): e1000100. doi:10.1371/journal.pmed.1000100. 
Shaia, J. S., \& Gonzenbach, W. J. (2007). Communications with Management in Times of Difficulty and Crisis: Silence Explained*.International Journal Of Strategic Communication, 1(3), 139. doi:10.1080/1553 1180701434777.

Stacks, D.W. (2017). Primer of public relations research $3^{\text {rd }}$ ed,. New York: The Guilford Press.

Tversky, A. \& Kahneman, D. (1981). The Framing of decisions and the psychology of choice. Science. 211(4481): 453-58. doi:10.1126/science.7455683

Wilcox, D.L., Cameron, G.T., \& Reber, B.H. (2015). Public relations: Strategies and Tactics $\left(11^{\text {th }}\right.$ ed.). New York: Pearson.

Wilbur, D. (2016). Defining the Iraq-Afghanistan Veteran in American Newspapers. Sociology Study 6(4), 267-276. doi: 10.17265/2159-5526/2016.04. Retrieved from http:/www.davidpublisher.com/Public/uploads/Contribute/57cd123f52eb8.pdf.

Wu, F., Cheng, Y., \& Chao, D. (2017). Global questioners: examining journalists' aggressiveness at Chinese premiers' press conferences (1993-2015). Asian Journal of Communication, 27(4), 357-377.

Yang, C. (2016A). Social Media Keep Buzzing! A Test of Contingency Theory in China's Red Cross Credibility Crisis. International Journal of Communication (19328036), 10, 3241-3260. 